\title{
B Cell Differentiation and Immunoregulatory T Cell Function in Human Cord Blood Lymphocytes
}

\author{
Giovanna Tosato, Ian T. Magrath, Irma R. Koski, Nancy J. Dooley, and \\ R. Michael Blaese, Metabolism Branch and Pediatric Oncology Branch, \\ National Cancer Institute, National Institutes of Health, \\ Bethesda, Maryland 20205
}

A B S T RACT The functional maturity of $\mathrm{T}$ and B lymphocyte populations from human newborns was evaluated using a reverse hemolytic plaque assay to detect immunoglobulin-secreting cells generated in in vitro cultures stimulated with pokeweed mitogen (PWM), a T cell-dependent polyclonal activator, and the Epstein-Barr virus (EBV), a T cell-independent $B$ cell activator. Cord blood lymphocytes failed to produce immunoglobulin in response to $\mathrm{PWM}$, but did respond with immunoglobulin synthesis to stimulation with EBV. Co-culture experiments demonstrated that cord blood $\mathrm{T}$ cells would inhibit immunoglobulin production by adult cells stimulated with PWM, but not with EBV. Cord blood T cells did suppress immunoglobulin production by cord blood $\mathrm{B}$ cells when stimulated with a mixture of EBV and PWM, indicating that cord blood, in contrast to adult blood, contains a population of suppressor $\mathrm{T}$ cell precursors that are easily activated by PWM. Irradiation of the cord blood T cells with 2,000 rad eliminated the suppressor activity and revealed normal helper function for immunoglobulin (Ig) $\mathrm{G}, \mathrm{A}$, and $\mathrm{M}$ when these $\mathrm{T}$ cells were co-cultured with adult B cells. Cord blood B cells co-cultured with adult $\mathrm{T}$ cells or irradiated cord blood $\mathrm{T}$ cells did produce immunoglobulin in response to PWM, but the response was significantly lower than that of adult B cells, and only IgM was produced in these cultures. These studies demonstrate that both the $T$ and $B$ cells of the human newborn have significant functional differences compared with the functions of $\mathrm{T}$ and $\mathrm{B}$ lymphocyte populations in adults.

\section{INTRODUCTION}

The immune status of the human neonate has been the subject of intense investigation for many years. Several features of the normal newborn immune sys-

Received for publication 29 January 1980 and in revised form 2 April 1980. tem are relatively distinctive, including the absence of endogenously produced immunoglobulin (Ig)G and IgA in the serum, and antibody responses primarily restricted to the IgM class in spite of the presence of normal adult numbers of circulating B lymphocytes bearing surface IgM, IgG, and IgA (1). In addition, when tested in vitro, cord blood lymphocytes appear deficient in their ability to differentiate into plasma cells when stimulated with pokeweed mitogen (PWM) ${ }^{1}$ $(2-5)$. Neonatal $T$ cells are functionally mature in terms of their capacity to respond to mitogens by proliferation, and neonatal monocytes have achieved full activity as effectors in antibody-dependent cellular cytotoxicity $(6,7)$. Previous studies have demonstrated that cord blood $\mathrm{T}$ cells inhibit in co-culture the proliferative responses of normal lymphocytes (8-11), and suppress PWM-induced differentiation of adult B cells into plasma cells in vitro $(4,5,12-14)$.

To clarify the contribution of lymphoid cell subsets to the relative unresponsiveness of the newborn, we have used a $T$ cell-independent activator, the EpsteinBarr virus (EBV), and a $T$ cell-dependent, macrophage-dependent mitogen, PWM, to evaluate the functional maturity of cord blood B and T cells. Our results suggest that combined $B$ and $T$ cell functional deficiencies account for the inability of newborns to express a normal antibody response in vitro.

\section{METHODS}

Peripheral blood leukocytes. Cord blood was obtained at the time of delivery from normal uncomplicated pregnancies. Only cord blood samples obtained from uncomplicated deliveries without systemic anesthesia were studied. Immediately after delivery, but before the expulsion of the placenta, cord blood was allowed to drain into tubes containing $\mathbf{0 . 5}$ $\mathrm{cm}^{3}$ of preservative-free heparin. Venous blood was also ob-

${ }^{1}$ Abbreviations used in this paper: EBV, Epstein-Barr virus; IgSC, immunoglobulin-secreting cells; MNC, mononuclear cell; PWM, pokeweed mitogen; RHPA, reverse hemolytic plaque assay. 


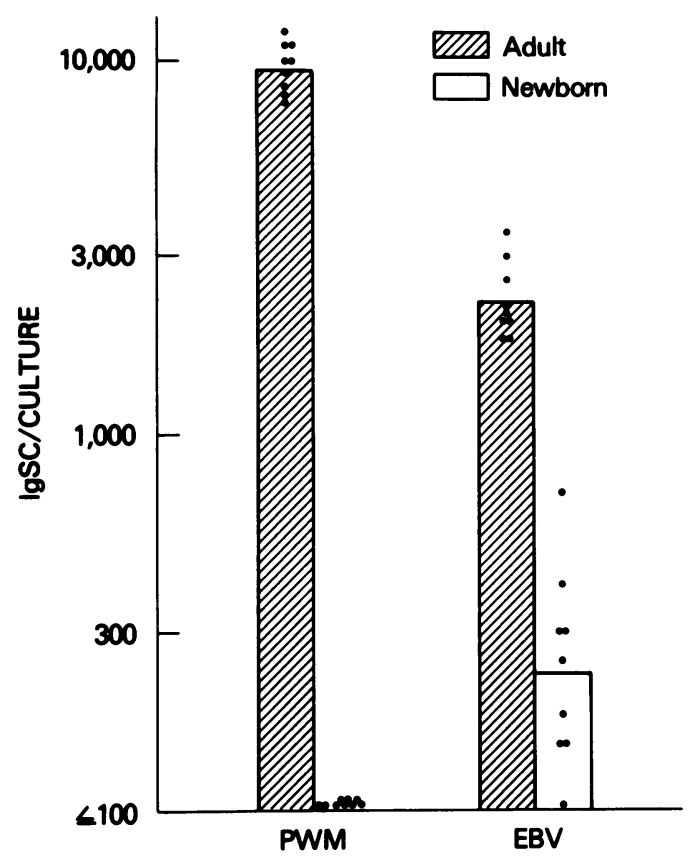

FIGURE 1 PWM-and EBV-induced immunoglobulin production in lymphocyte cultures $\left(1 \times 10^{6} \mathrm{MNC}\right)$ from nine normal adults and nine normal cord blood samples.

tained from healthy adult volunteers. Heparinized blood was mixed in a $8: 1$ ratio with $6.5 \%$ dextran in saline and incubated at $37^{\circ} \mathrm{C}$ for $20-30 \mathrm{~min}$. Neonatal and adult blood specimens were handled in the same manner. A preliminary dextran sedimentation was used because direct centrifugation of cord blood over Ficoll-Hypaque gradients causes heavy erythrocyte contamination of the gradient interface. The leukocyte-rich plasma was collected and centrifuged through a gradient of Ficoll-Hypaque (LSM solution, Bionetics Laboratory Products, Litton Bionetics Inc., Kensington, Md.). Mononuclear cell suspensions containing $<2 \%$ granulocytes were collected at the interface of these gradients. This cell suspension containing $\sim 80 \%$ lymphocytes and $20 \%$ monocytes will be referred to as "mononuclear cell (MNC) population." Cell subsets enriched for T or B cells were obtained by incubating the MNC populations for $2 \mathrm{~h}$, at $4^{\circ} \mathrm{C}$, at a ratio of $1: 150$ with 2 -aminoethylisothiouroniumbromidetreated sheep erythrocytes and separating the rosette-forming cells on another Ficoll-Hypaque gradient (15). Nonrosetting MNC were collected at the interface of the gradient. This cell suspension containing $<2 \% \mathrm{~T}$ cells and a variable number of monocytes will be referred to as the "B cell population." The pellet of rosetted MNC was resuspended and spun through a second Ficoll-Hypaque gradient. A second centrifugation over Ficoll-Hypaque gradients reduces the number of contaminating nonrosetting cells in the pellets. The rosetted lymphocyte population was treated with ammonium chloridelysing buffer to remove sheep erythrocytes. This cell suspension containing $<2 \%$ nonrosetting cells will be referred to as the "T cell population."

Lymphocyte cultures. All cell populations were washed extensively in balanced salt solution and suspended in RPMI 1640, supplemented with $2 \mathrm{mM}$ glutamine, $100 \mathrm{IU} / \mathrm{ml}$ streptomycin, and $10 \%$ heat-inactivated fetal bovine serum (all reagents from Gibco Laboratories, Grand Island Biological
Co., Grand Island, N. Y.). The cells were cultured at various concentrations in $16 \times 125-\mathrm{mm}$ round bottom tubes (Falcon Labware, Div. of Becton, Dickinson \& Co., Oxnard, Calif.) at $37^{\circ} \mathrm{C}$ with or without the addition of EBV and/or PWM. Mononuclear cells and B cells, when cultured alone, were set up at $1.0 \times 10^{6}$ and $0.5 \times 10^{6} / \mathrm{ml}$, respectively; in co-culture experiments, $0.5 \times 10^{6} \mathrm{~B}$ cells or $0.5 \times 10^{6} \mathrm{MNC}$ were mixed with $2.0 \times 10^{6} \mathrm{~T}$ cells. EBV was obtained from supernates of B95-8 continuous cell cultures, as previously described (16), and added at a final dilution of $50 \mu \mathrm{l} / \mathrm{ml}$ of culture. PWM was added at a final concentration of $10 \mu \mathrm{l} / \mathrm{ml}$. After $7 \mathrm{~d}$, the cultured cells were washed three times in balanced salt solution and the number of immunoglobulin-secreting cells (IgSC) was assessed in a reverse hemolytic plaque assay.

Reverse hemolytic plaque assay (RHPA). The principles of the RHPA have been previously described (17-19). Briefly, $0.1 \mathrm{ml}$ of the suspension to be tested was added to $0.25 \mathrm{ml}$ of $1.12 \%$ agarose (Sea Plaque, Marine Colloids, Inc., Rockland, Maine) preheated to $43^{\circ} \mathrm{C}$ in $10 \times 75-\mathrm{mm}$ glass culture tubes. Then $0.025 \mathrm{ml}$ of a $30 \%$ suspension of protein A-treated sheep erythrocytes was added to the tubes; the contents were mixed and transferred to $60 \times 15-\mathrm{mm}$ petri dishes that had been precoated with $4 \mathrm{ml}$ of $2.5 \%$ agarose. The petri dishes were quickly swirled to distribute the cell-agar mixture into a uniform monolayer. $1 \mathrm{ml}$ of appropriately diluted polyvalent rabbit anti-human antisera (with specificity for $\mathrm{G}, \mathrm{A}, \mathrm{M}, \mathrm{K}$, and L) or solid-phase absorbed class-specific rabbit antisera (with specificity for $G, A$, or $M$ heavy chains) was added to each dish. After $1 \mathrm{~h}$-incubation at $37^{\circ} \mathrm{C}, 1 \mathrm{ml}$ of sheep erythrocyte-absorbed guinea pig complement (Gibco Diagnostics Laboratories) diluted 1:8 was added. After an additional hour of incubation, the supernatant fluid was aspirated and the number of plaques was determined under $7 \times$ magnification. Results are expressed as total number of IgSC per culture (means of duplicate determinations). The RHPA is used to determine the total number of IgSC present at any point in time in a given lymphocyte culture, regardless of the specificity of the antibody produced by those cells. This assay differs from competitive radioimmunoassays that measure the cumulative amount of immunoglobulin secreted into the culture media over the period of culture. Results obtained with the RHPA in our experience closely parallel those obtained with the radioimmunoassay. The immunoglobulin-secreting cell response in each group is expressed as the geometric mean. The statistical significance of differences between group means was determined with a two-tailed $t$ test.

\section{RESULTS}

In vitro plaque-forming cell response to $P W M$ and $E B V$. The in vitro plaque-forming cell response to EBV has been shown to be $T$ cell independent in adults (16), while the response to PWM is T cell and macrophage dependent (20-23). The ability of cord blood MNC to respond to either PWM or EBV is shown in Fig. 1. Cord blood MNC clearly were able to generate IgSC when cultured with EBV, although the response was quantitatively reduced when compared with that of normal adults. The mean response for normal adult $\mathrm{MNC}$ in the presence of $\mathrm{EBV}$ was 1774

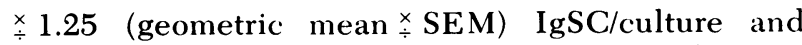
237 (1.15) IgSC/culture for neonatal lymphocytes $(P<0.001)$. By contrast, virtually no IgSC were generated in neonatal lymphocyte cultures stimulated with 


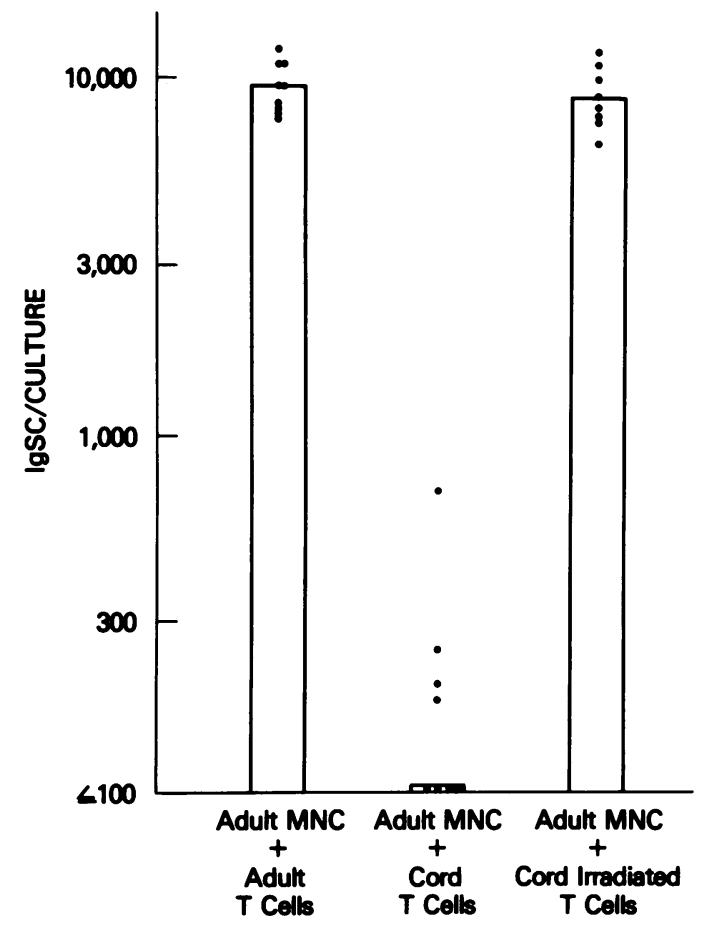

FIgURE 2 Inhibition of IgSC generation by normal MNC cocultured with neonatal T cells in the presence of PWM and abolition of this suppressor activity by irradiation of the $T$ cells with 2,000 rad. Normal MNC $\left(0.5 \times 10^{6}\right)$ were cultured with $2 \times 10^{6}$ adult or cord T cells.

PWM. Purified cord blood B cell suspensions also produced a detectable plaque-forming cell response to EBV, although again this was reduced when compared with that of normal adults. In 10 experiments the mean number of IgSC was 2595 (1.16) for adult B lymphocytes and 551 (1.08) for cord blood ( $P$ $<0.001$ ).

Neonatal T cells suppress PWM-induced plaqueforming cell responses. To determine the basis for the failure of cord blood cells to respond to PWM, a variety of co-culture experiments were performed combining cord and adult lymphocyte populations. First, normal adult MNC were co-cultured with cord blood $\mathrm{T}$ cells in the presence of PWM. Fig. 2 summarizes eight such co-culture experiments. Our results indicate that cord blood $\mathrm{T}$ cells suppressed by $>80 \%$ the PWM-induced generation of IgSC of the co-cultured adult lymphocytes. The suppression was prevented by preirradiation of the cord blood $T$ cells with 2,000 rad. These findings suggested that the failure of the neonatal MNC to respond to PWM might be actively mediated by a radiosensitive suppressor $\mathrm{T}$ cell. Since the neonatal MNC responded to EBV however, the possibility that this suppressor cell might require PWM for its activation was further examined. Both PWM and EBV were therefore added simultaneously
TABLE I

Polyvalent IgSC Responses from Newborn and Adult MNC Cultured with PWM, EBV, and PWM +EBV

\begin{tabular}{clrrr}
\hline \multirow{2}{*}{ Experiment } & \multirow{2}{*}{$\begin{array}{c}\text { Type of } \\
\text { culture* }\end{array}$} & PWM & EBV & PWM + EBV \\
\cline { 3 - 5 } & & \multicolumn{3}{c}{ plaques/culturet } \\
\multirow{2}{*}{1} & Cord & 0 & 640 & 40 \\
& Adult & 7,500 & 2,300 & 8,000 \\
2 & Cord & 0 & 700 & 40 \\
& Adult & 7,800 & 1,800 & 9,200 \\
3 & Cord & 0 & 520 & 20 \\
& Adult & 5,800 & 1,500 & 7,900 \\
\hline
\end{tabular}

* 7-d cultures of $1 \times 10^{6} \mathrm{MNC}$ from newborn infants and normal adult individuals.

† Developed with polyvalent reagent.

to cultures of cord and adult blood MNC. As shown in Table I, adult MNC responded very well to this double mitogenic stimulus, 8346 (1.05) IgSC, although the response of cord MNC was profoundly depressed compared with the response induced by EBV alone: 31 (1.05) vs. 615 (1.09), $P<0.001$. Thus, although cord blood $T$ cells do not spontaneously suppress the response to $\mathrm{EBV}$, these cells exhibit strong suppressor activity after exposure to the $\mathrm{T}$ cell-dependent polyclonal activator, PWM.

Cord blood $T$ cells provide normal helper activity. The ability of neonatal $\mathrm{T}$ cells to provide helper function was examined taking advantage of the observation that the activity of suppressor $T$ cells is relatively radiosensitive, as opposed to the activity of helper $\mathrm{T}$ cells (24). Thus, irradiated (2,000 rad) cord blood T cells were co-cultured with neonatal or adult $B$ cells in the presence of PWM. As a control, irradiated adult T cells were employed. As shown in Fig. 3, irradiated neonatal $\mathrm{T}$ cells provided help for both neonatal and adult $B$ cells. The mean value for IgSC generated by $0.5 \times 10^{6}$ neonatal B cells co-cultured with $2.0 \times 10^{6}$ neonatal or adult irradiated $\mathrm{T}$ cells was, respectively, $2432(1.14)$ and $1943(1.21)(P=0.5)$; for adult $B$ cells co-cultured with neonatal or adult $T$ cells, the mean responses were 9688 (1.08) and 9372 (1.10), respectively $(P=0.75)$. In addition, the relative frequency of IgSC of each class was similar in cocultures of adult $B$ cells with either adult or neonatal irradiated $\mathrm{T}$ cells, indicating that neonatal $\mathrm{T}$ cells provide normal helper function for each class of IgSC (Table II).

Class distribution of IgSC generated by cord blood $B$ cells. The class distribution of IgSC generated by cord blood B cells was determined by developing the plaques in the RHPA with isotype-specific rabbit anti- 


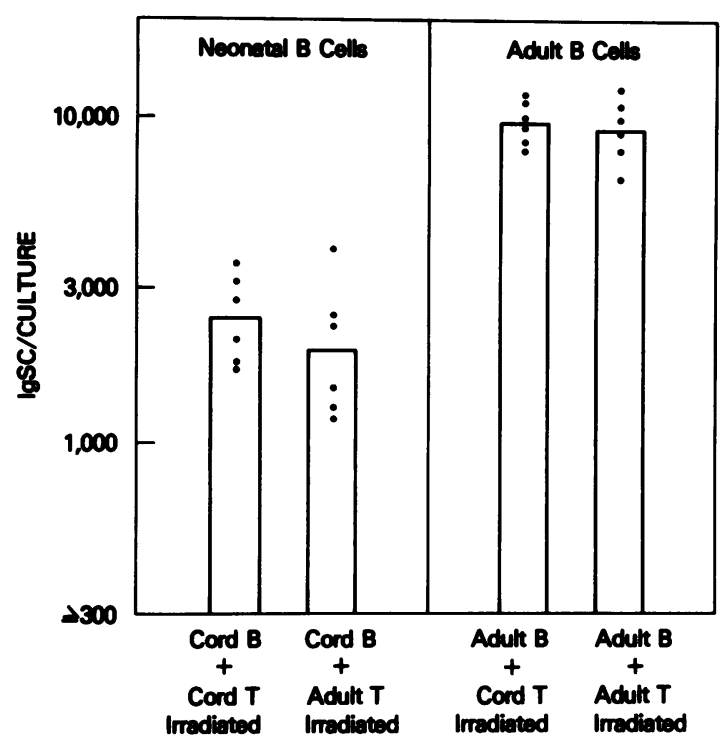

FIgURE 3 PWM-induced, IgSC responses obtained from 0.5 $\times 10^{6}$ neonatal or adult $B$ cells cultured with $2 \times 10^{6}$ neonatal or adult irradiated $(2,000 \mathrm{rad}) \mathrm{T}$ cells.

human IgG, IgA, or IgM antisera. Cord blood B cells activated by EBV or PWM in the presence of adult helper $T$ cells were examined. As shown in Table III, cord blood B cells produced only IgM-secreting cells; no IgG- or IgA-secreting cells could be identified. In addition, the relative frequency of IgM-secreting cells in cultures of cord blood B cells was lower than in cultures of adult $B$ cells. This finding suggests that cord blood B cells are qualitatively and quantitatively deficient in their capacity to generate IgSC.

\section{DISCUSSION}

Both $B$ and $T$ cells of human newborns have significant functional differences when compared with the $B$ and $T$ lymphocyte populations in adults. These differences account for the impaired immunoglobulin production of human newborn lymphocytes in vitro and may also help to understand the mechanisms underlying impaired antibody responses in vivo.

Cord blood $\mathrm{T}$ cells consistently suppressed in coculture the activation of B lymphocytes into IgSC in the presence of a $\mathrm{T}$ cell-dependent activator, PWM. The specificity of these neonatal suppressor $T$ cells is without apparent preference for an individual immunoglobulin class. In addition, the suppression is not specific for neonatal lymphocytes, because PWMinduced responses of adult mononuclear cells are also markedly suppressed. Interestingly, cord blood mononuclear cells, although unable to produce significant quantities of immunoglobulin when cultured with PWM, did generate IgSC in cultures stimulated with a T cell-independent activator, EBV. Only when PWM was added to the cultures did the neonatal $T$ cells suppress immunoglobulin production. This observation suggests that cord blood $\mathrm{T}$ cells, unlike normal adult $T$ cells, are triggered by PWM to become activated suppressor cells that prevent the differentiation of B cells into IgSC.

This pattern is not observed in most diseases associated with increased suppressor $\mathrm{T}$ cell activity, such as common variable hypogammaglobulinemia and infectious mononucleosis (25). T cells obtained from these patients are usually able to suppress the in vitro generation of IgSC in the presence of T cellindependent B cell activators such as Nocardia and EBV, in addition to PWM. This suggests that the suppressor $\mathrm{T}$ cells in human newborns either belong to a different cell subset, or are perhaps functionally immature in that they require activation to express their suppressor function.

Previous reports have suggested that lymphoid cells from human newborns inhibit the proliferative responses of normal adult lymphocytes stimulated with mitogens or allogeneic cells $(8-11)$. Similarly, and in

TABLE II

Class Distribution of IgSC Produced by PWM-activated Adult B Cells Cultured with Adult or Neonatal Irradiated T Cells

\begin{tabular}{lcccc}
\hline \multicolumn{1}{c}{ Type of culture* $^{*}$ Experiment } & IgG & IgA & IgM \\
\hline & & & plaques/culture \\
Adult B cells & 1 & 8,200 & 3,500 & 4,900 \\
$\quad+\quad$ & 2 & 7,200 & 1,280 & 1,800 \\
Adult irradiated T cells & 3 & 6,400 & 2,400 & 3,100 \\
Adult B cells & 1 & 8,400 & 2,800 & 2,400 \\
$\quad+\quad$ & 2 & 6,400 & 1,100 & 2,200 \\
Neonatal irradiated T cells & 3 & 5,520 & 1,200 & 2,950 \\
\hline
\end{tabular}

B cells alone stimulated with $\mathrm{PWM}$ produced $<10 \mathrm{IgSC} /$ culture.

${ }^{*}$ B cells $\left(0.5 \times 10^{6}\right)$ were cultured with $2 \times 10^{6}$ irradiated $(2,000 \mathrm{rad}) \mathrm{T}$ cells. 
TABLE III

Class Distribution of IgSC Generated by EBV-and PWM-activated Cord Blood

\begin{tabular}{cccccc}
\hline & \multicolumn{5}{c}{ B Cells } \\
\hline Cells cultured & Activator & Experiment & IgG & IgA & IgM \\
\hline & & & & plaques/culture \\
Neonatal B cells & EBV & 1 & 0 & 0 & 180 \\
& & 2 & 0 & 0 & 220 \\
& & 3 & 0 & 0 & 260 \\
Neonatal B cells & PWM & 1 & 0 & 0 & 1,400 \\
(with normal help) & & 2 & 10 & 0 & 1,200 \\
& & 3 & 0 & 0 & 1,750 \\
\hline
\end{tabular}

* Neonatal B cells $\left(0.5 \times 10^{6}\right)$ were cultured with EBV, or mixed with adult irradiated $(2,000 \mathrm{rad}) \mathrm{T}$ cells $\left(2 \times 10^{6}\right)$ and stimulated with PWM.

agreement with our observations, most studies $(4,5$, 12-14) have presented evidence for neonatal $\mathrm{T}$ cell suppressor activity for B cells stimulated with PWM.

Recent studies have attempted to characterize further the $\mathrm{T}$ cell subset responsible for the suppressor function in cord blood. Oldstone et al. (12) found that these suppressor cells bear Fc IgG receptors; Hayward et al. (13) indicate that these T cells bear Fc IgM receptors; and Durandy et al. (4) detected suppressor $\mathrm{T}$ cells both in $\mathrm{T} \gamma$-enriched and $\mathrm{T} \gamma$-depleted populations.

Cord blood B cells appear to be functionally defective in their capacity to generate IgSC in vitro when compared with adult lymphocytes. This B cell function was evaluated, after removal of the T cells, by stimulating cord blood B cells in culture with either EBV or $\mathrm{PWM}$, in the presence of normal $\mathrm{T}$ cell help. Under these conditions, cord blood lymphocytes produced only small numbers of IgSC restricted to the IgM class, while no significant IgA- or IgG-secreting cells were obtained. In agreement with our findings, Hayward et al. (3) and Durandy et al. (4) have shown that the PWM-induced differentiation of neonatal B cells into plasma cells could be enhanced by normal adult helper cells. Morito et al. (5) found meager immunoglobulin production by cord blood B cells even in the presence of allogeneic adult helper $\mathrm{T}$ cells. Interestingly, although B cell activation into IgSC is deficient in the newborn as compared with the adult, at birth the percentage of peripheral blood B lymphocytes staining for surface-bound IgG, IgA, and IgM is within the range found in the peripheral blood of adult subjects ( 1 ). This indicates that in human ontogeny there is a physiologic lag between the emergence of $\mathrm{B}$ lymphocytes and their ability to generate IgSC of all classes. It is tempting to speculate that the subset of patients with common variable hypogammaglobu linemia characterized by normal B cell profiles and normal IgM but absent IgG and IgA production may share a similar basis with this "physiologically limited" $B$ cell activation of the normal human neonate.

\section{REFERENCES}

1. Gathings, W. E., A. R. Lawton, and M. D. Cooper. 1977. Immunofluorescent studies of the development of pre-B cells, B lymphocytes and immunoglobulin isotype diversity in humans. Eur. J. Immunol. 7: 804-810.

2. Wu, L. Y. F., A. Blanco, M. D. Cooper, and A. R. Lawton. 1976. Ontogeny of B-lymphocyte differentiation induced by pokeweed mitogen. Clin. Immunol. Immunopathol. 5: 208-217.

3. Hayward, A. R., and A. R. Lawton. 1977. Induction of plasma cell differentiation of human fetal lymphocytes: evidence for functional immaturity of $\mathrm{T}$ and B cells. $J$. Immunol. 119: 1213-1217.

4. Durandy, A., A. Fisher, and C. Griscelli. 1979. Active suppression of B lymphocyte maturation by two different newborn $\mathrm{T}$ lymphocyte subsets. J. Immunol. 123: 2644-2650.

5. Morito, T., A. D. Bankhurst, and R. C. Williams. 1979. Studies of human cord blood and adult lymphocyte interactions with in vitro immunoglobulin production. J. Clin. Invest. 64: 990-995.

6. Schechter, B., Z. T. Handzel, Y. Altman, E. Nir, and S. Levin. 1977. Cellular immunity in newborn infants and children: stimulation of lymphocyte protein synthesis as a measure of immune competence. Clin. Exp. Immunol. 27: 478-484

7. Milgrom, H., and S. L. Shore. 1977. Assessment of monocyte function in the normal newborn infant by antibodydependent cellular cytotoxicity. J. Pediatr. 91: 612-614.

8. Olding, L. B., and M. B. A. Oldstone. 1974. Lymphocytes from human newborns abrogate mitosis of their mother's lymphocytes. Nature (Lond.). 249: 161-162.

9. Lawler, S. D., E. O. Ukaejiofo, and B. R. Reeves. 1975. Interaction of maternal and neonatal cells in mixed lymphocyte cultures. Lancet. II: 1185-1187.

10. Olding, L. B., and M. B. A. Oldstone. 1976. Thymusderived peripheral lymphocytes from human newborns inhibit division of their mothers lymphocytes. J. Immunol. 116: 682-686.

11. Olding, L. B., R. A. Murgita, and H. Wigzell. 1977. Mitogen-stimulated lymphoid cells from human new- 
borns suppress the proliferation of maternal lymphocytes across a cell impermeable membrane. J. Immunol. 119: 1109-1114.

12. Oldstone, M. B. A., A. Tishon and L. Moretta. 1977. Active thymus-derived suppressor lymphocytes in human cord blood. Nature (Lond.). 269: 333-335.

13. Hayward, A. R., and P. M. Lydyard. 1978. Suppression of B lyntphocyte differentiation by newborn $\mathrm{T}$ lymphocytes with an Fc receptor for IgM. Clin. Exp. Immunol. 34: 374-378.

14. Miyawaki, T., H. Seki, M. Kubo, and N. Taniguki. 1979. Suppressor activity of $\mathrm{T}$ lymphocytes from infants assessed by coculture with unfractionated adult lymphocytes in the pokeweed-mitogen system. J. Immunol. 123: $1092-1096$.

15. Pellegrino, M. A., S. Ferrone, M. P. Dietrich, and R. A. Reisfeld. 1975. Enhancement of sheep red blood cell human lymphocyte rosette formation by the sulphydril compound 2-amino-ethylisothiouronium. Clin. Immunol. Immunopathol. 3: 324-327.

16. Kirchner, H., G. Tosato, R. M. Blaese, S. Broder, and I. T. Magrath. 1979. Polyclonal immunoglobulin secretion by human B lymphocytes exposed to Epstein-Barr virus in vitro. J. Immunol. 122: 1310-1313.

17. Ginsburg, W. W., F. D. Finkelman, and P. E. Lipsky. 1978. Circulating mitogen-induced immunoglobulin-secreting cells in human peripheral blood. Evaluation by a modified reverse hemolytic plaque assay. J. Immunol. 120: 33-39.

18. Blaese, R. M., C. E. Lawrence, A. V. Muchmore, J.
Grayson, N. J. Dooley, and I. R. Koski. 1979. Immunoglobulin secreting cells in the circulating blood and in mitogen stimulated cultures from patients with immunodeficiency. In: Antibody Production in Man. A. S. Fauci and R. Ballieux, editors. Academic Press, Inc., New York. 325-331.

19. Lawrence, E. C., R. M. Blaese, and R. R. Martin. 1978. Immunoglobulin secreting cells in normal human lavage fluids. J. Clin. Invest. 62: 832-835.

20. Janossi, G., and M. Greaves. 1975. Functional analysis of murine and human B lymphocyte subsets. Transplant. Rev. 24: 177-236.

21. Keightley, R. G., M. D. Cooper, and A. R. Lawton. 1976. The $T$ cell dependency of $B$ cell differentiation induced by pokeweed mitogen. J. Immunol. 117: 1538-1544.

22. Saxon, A., R. H. Stevens, and R. F. Ashman. 1977. Regulation of immunoglobulin production in human peripheral blood leukocytes: cellular interactions. $J$. Immunol. 118: 1972-1979.

23. Knapp, W., and G. Baumgartner. 1978. Monocyte-mediated suppression of human $B$ lymphocyte differentiation in vitro. J. Immunol. 121: 1177-1182.

24. Siegal, F. P., and M. Siegal. 1977. Enhancement by irradiated $\mathbf{T}$ cells of human plasma cell production: dissection of helper and suppressor functions in vitro. $J$. Immunol. 118: 642-647.

25. Tosato, G., I. T. Magrath, I. Koski, N. Dooley, and R. M. Blaese. 1979. Suppressor T cell activation during EpsteinBarr virus-induced infectious mononucleosis. N. Engl.J. Med. 301: 1133-1137. 